\title{
Integração das linguagens artísticas: formação continuada de professores da Educação Básica
}

\author{
Integration of artistic languages: continuing education for Basic Education teachers \\ Dorcas Janice Weber \\ *Universidade Federal do Rio Grande do Sul / Brasil e Universidade do Minho
}

\begin{abstract}
Resumo
As práticas relacionadas ao ensino da Arte no contexto escolar brasileiro ainda estão distantes do que sugere a legislação vigente e do que vem sendo debatido no âmbito acadêmico. Professores com formação insuficiente e falta de apoio restringem suas práticas refletindo em uma ação docente considerada superficial. Em busca de ações que auxiliem professores que estão à frente do ensino da Arte nas escolas, foi desenvolvida uma proposta de curso de formação continuada na busca por proporcionar um conhecimento acerca de elementos básicos das diferentes linguagens artísticas sugeridas pela legislação educacional.
\end{abstract}

Palavras clave: Ensino de Arte, Integração artística, Formação continuada.

\begin{abstract}
Practices related to art education in Brazilian school context are still far from suggesting the current and what is being debated in the academic regulations. Teachers with inadequate training and lack of support restrict their practices reflecting on a teaching action considered superficial. In pursuit of actions to assist teachers who are ahead of art education in schools, a proposal for a continuing education course in the search was developed for providing knowledge about basic elements of the different artistic languages suggested by educational legislation.
\end{abstract}

Keywords:Art: Education, Artistic integration, Continuing education.

\section{Introdução}

A Arte no contexto da educação brasileira tem se caracterizado por diferentes concepções e práticas pedagógicas. Os documentos legais vigentes sugerem que o ensino da Arte se constitue em um componente curricular na qual estejam envolvidas diferentes linguagens artísticas, para tal estão sugeridas as Artes Visuais, Música, Dança e Teatro. Nas práticas observadas junto ao espaço escolar, tais sugestões, que já estão em vigor há quase duas décadas, ainda não estão amplamente colocadas em prática. Diferentes aspectos podem ser apontados para explicar a atual situação, contudo, o fator que ressalta é a formação dos profesores que atuam com o ensino da Arte no espaço escolar. Assim, vale destacar três tipos de professores, aqueles que possuem formação específica em uma linguagem artística, aqueles que não possuem nenhuma formação em Arte e, aqueles que possuem pouquíssima formação em Arte junto à sua formação. Estes últimos, em geral, com formação em Pedagogia (curso de formação de professores para a Educação Infantil ou anos iniciais do Ensino Fundamental). De todo modo, pensar em uma formação que abarque as quatro linguagens sugeridas caracteriza um retrocesso, um retorno à polivalência, no ensino da Arte brasileiro. Então, é preciso proporcionar aos professores conhecimento, ainda que mínimo, acerca das diferentes linguagens artísticas, de modo que possam transitar e estabelecer relações entre elas de maneira mais familiar durante sua prática pedagógica. Em busca de compreender e refletir sobre estratégias de mudança, buscou-se em Pourtois \& Desmet (1997), Debord (1977), Barbosa (2005) e (2008), entre outros, referencial teórico. Tendo em conta o contexto acima, foi desenvolvido um curso de formação continuada para professores atuantes com o componente curricular Arte na Educação Básica brasileira. O curso denominado "Arte na Educação Básica", tomou como ponto de partida os espetáculos escolares, termo que faz referência às festividades comumente presentes no espaço escolar. A partir disso, possibilitou-se o estudo dos diferentes espetáculos originários nas diferentes linguagens da Arte, posibilitando, assim, um olhar ampliado sobre este campo do conhecimento. A ação foi desenvolvida como ação de extensão universitária e ofertada para professores de escolas públicas do estado do Rio Grande do Sul/RS, localizado no sul do Brasil, sob a modalidade semi-presencial. Os resultados reafirmaram a necessidade de formação continua em Arte para os profesores que atuam com Arte na escola, principalmente aqueles com formação em pedagogía.

\section{Proposta}

Tendo em conta a perspectiva da formação integral e interartística foi proposta uma formação continuada em Artes para cento e vinte (120) professores da Educação Básica atuantes nas Redes Públicas de Ensino do Rio Grande do Sul denominada 'Arte na Educação Básica: espetáculos escolares'. A proposta é uma das ofertas de Formação Continuada de Professores da Universidade Federal do Rio Grande do Sul (UFRGS), realizada como ação de extensão na modalidade semipresencial, com encontros presenciais de inicio e final de curso. Os alunos, em sua maioria com formação em pedagogia, foram organizados em grupos distintos alocados em polos de apoio tutorial presencial, localizados nos municípios de Camargo, Seberi, Santo Antonio da 
Patrulha e São Francisco de Paula, no estado do Rio Grande do Sul, Brasil. A carga horária total de noventa (90) horas, foi dividida em: vinte (20) horas em ações presenciais realizados em dois (02) momentos e setenta (70) horas destinadas às práticas a distância. A proposta abrangeu as linguagens de Artes Visuais, Música e Dança, propondo um olhar interartístico sobre temas disponibilizados aos alunos semanalmente em quinze (15) Unidades de Estudos.

\section{Objetivo}

Proporcionar formação ampliada em Arte para professores em exercício no ensino de arte a fim de fortalecer e ampliar comunidades virtuais de formação continuada em Artes estimulando o uso de tecnologias educacionais em uma proposta integral e interartística.

\section{Justificativa}

A disciplina escolar denominada Artes prevê, nos documentos legais, conteúdos que abrangem diferentes linguagens artísticas a serem ministrados por professores com formação específica. A realidade desta disciplina no espaço escolar mostra-se bastante divergente do que descreve a legislação. A formação inicial, ainda, não supre as necessidades que a escola tem para cumprir as leis. Considerando que a legislação sugere a abrangência de quatro (04) linguagens na educação em Arte na Educação Básica, professores de diferentes linguagens da Arte deveriam estar alocados nas escolas. Então, o número de professores que saem das universidades a cada ano ainda não supre as demandas das escolas. Mesmo onde existem professores habilitados, nem sempre há professores de todas as linguagens, e assim, também não respondem integralmente a legislação. Em muitas instituições é exigido do professor que está à frente da disciplina de Artes o conhecimento de diferentes linguagens, contudo, não é papel de um único professor assumir a polivalência e atender integralmente a todas as linguagens. É interessante que os professores estejam familiarizados com as linguagens a ponto de transitar confortavelmente entre elas e estabelecer relações.

$\mathrm{Na}$ tentativa de solucionar tais problemas, que decorrem da legislação, as administrações escolares, recorrem a professores com interesse e/ou tempo disponíveis, independente de sua formação, para suprir essa carga horária que fica obsoleta por não ter um profissional específico. Vale atentar aos Parâmetros Curriculares Nacionais (PCN) quando citam que a formação insuficiente aliada à carência de materiais de qualidade que dêem suporte às práticas escolares, possibilita que sejam desenvolvidas atividades a partir de ideias "preconcebidas que reduzem a atividade artística na escola a um verniz de superfície, que visa as comemorações de datas cívicas e enfeitar o cotidiano escolar" (Brasil, 1997, p 31). Este alerta refere-se às muitas práticas do ensino de Arte realizadas junto às festividades e comemorações promovidas pela escola nas quais as propostas voltam-se mais para o preparo de apresentações e ao adorno do espaço escolar, distanciando da importância do conhecimento adquirido durante o processo de trabalho com os alunos.

Mesmo que a legislação apresente objetivos distintos das atividades supracitadas, os professores atuantes no ensino de Arte são fortemente cobrados e convocados para desenvolver ações em eventos comemorativos que ocorrem na escola. Uma explicação para a realização de tais práticas está na formação dos professores que ensinam Arte. Assim, apenas parte daqueles que estão a ensinar arte na escola possuem habilitação e conhecimentos específicos, logo, muitos estão despreparados para alcançar os objetivos da disciplina.

Pourtois e Desmet (1997) alertam que "cada um de nós incorporou em si próprio um modelo pedagógico, o que se viveu na infância, e tende a reproduzi-lo, quando por sua vez se torna educador. Assim, todo o adulto apresenta uma identidade pedagógica, que é a forma como ele interiorizou os valores e as práticas educativas que encontrou na sua primeira infância, durante a sua socialização" (p. 209). No âmbito da disciplina "Artes", a carência de professores para suprir as vagas acaba por trazer ao posto professores de diferentes áreas que trazem apenas a sua experiência, de quando foram alunos, para a sua docência. Ao longo do histórico desta disciplina várias práticas foram realizadas e, muitas delas, por artesãos e artistas autodidatas e, são essas vivencias que também permeiam as práticas da disciplina Artes e que, posteriormente, são reproduzidas por aqueles que não têm formação específica. Deste modo, se compreende como as práticas realizadas em tempos atrás ainda se fazem tão presentes atualmente.

O ensino de Arte precisa acompanhar as concepções e práticas artísticas além de integrar-se às tendências pedagógicas. As atuais produções artísticas apontam uma diversidade de produções e, em muitos casos, observa-se uma mescla de linguagens em uma única produção, como bem apontam Arslan e Iavelberg (2006). Neste caso, a integração de diferentes linguagens desponta outra linguagem, como é o caso das produções do cinema e de musicais. Do mesmo modo que tais produções unem linguagens em sua produção, a sua leitura e compreensão exige do espectador conhecimento ampliado e diverso. A leitura de mundo, assim como a compreensão das produções artísticas, é efetivada pelo reconhecimento dos símbolos e signos advindos das culturas que os produzem. Por isso, a necessidade de uma "imersão na linguagem artística e ao mesmo tempo uma reflexão crítica e contextual" (Coutinho, 2008, p. 156). Tal imersão deve abranger pluralidades de produções artístico culturais, de forma que seja possível compreender as diferentes linguagens ao máximo. São essas concepções que devem permear a formação de professores.

De acordo com Pourtois e Desmet (1997) mesmo após a formação universitária, inicial, as experiências vividas ao longo do processo de escolarização se fazem presentes. Ou seja, mesmo aqueles professores que passaram pela formação específica, ainda estes, reproduzem ações vividas na escola no momento em que eram alunos. Fato que reafirma a necessidade do professor manter-se em constante formação a fim de que 
internalize outras concepções que vão além daquilo que vem sendo realizado.

O ensino de Arte escolar possui papel fundamental na educação estética e a formação de um indivíduo crítico e reflexivo, a fim de reconhecer e compreender as produções que constituem o ambiente social e culturalmente. No entanto, as práticas desenvolvidas têm andado em direção contrária aos objetivos da disciplina. Neste texto, busca-se voltar atenção para a formação continuada de professores em atuação no ensino de arte, apresentando uma proposta de modelo integrado/integrador e específico, que apresenta linguagens artísticas específicas para a atuação docente em práticas multidisciplinares, mediada por tecnologias da informação e comunicação realizada no Rio Grande do Sul / Brasil.

\section{Conteúdos abordados}

As limitações de conhecimento acerca do ensino de Arte e as práticas enfocadas em comemorações escolares apontaram a necessidade de apresentar temas que abordassem diferentes linguagens de Arte sob um olhar diferenciado àquelas atividades que apontam para o desenvolvimento de eventos comemorativos que costumam aparecer no espaço escolar. Possibilitando, assim, outro modo de olhar para os espetáculos que ocorrem na escola, bem como para as práticas pedagógicas. Assim, ficaram definidos os seguintes temas:

Espetáculos Escolares - conceitos e definições

Artes Visuais

Cinema

Circo

Música

Dança

Teatro

Literatura

Arquitetura

Festas populares

Meios de comunicação de massa

Esporte, Moda e Eventos

Projetos Culturais na Escola

Produções Artísticas na Escola

Escola na Comunidade

\section{Metodologia}

Ao longo dos últimos anos, em várias experiências em formação continua e, mesmo edições semelhantes a esta que aqui se apresenta, apontaram a ânsia de muitos professores por "receitas prontas" e modelos que possam ser aplicados quase que de maneira imediata na sala de aula e, com isso são motivados a buscar formação. Contudo, a experiência dos professores como alunos possibilita maior segurança para sua prática posterior como professor. Por isso, optou-se por metodologias que propunham a formação do professor e não a oferta de modelos. Deste modo, as proposições oportunizaram vivencias e práticas por meio das atividades individuais e coletivas no decorrer do curso.

Tais propostas foram realizadas tanto por meio de atividades presenciais, nos polos, e a distância no
Ambiente Virtual de Aprendizagem (AVA) Moodle Institucional da Universidade Federal do Rio Grande do Sul (UFRGS). Com relação ao Moodle, tal ambiente foi organizado de modo que cada atividade teve seu local definido previamente. Assim, seis partes principais organizaram as atividades e informações do curso no AVA (Figura 1), quais sejam:

Menu geral: localizado na parte superior do espaço do AVA é onde os alunos podem buscar informações gerais sobre diferentes assuntos que dizem respeito ao curso.

Meu polo na internet: espaço onde os alunos estão organizados por pólo no qual fizeram sua inscrição e onde buscavam apoio presencial do tutor. Neste espaço são compartilhadas informações específicas de cada polo.

Parceiros na Rede: local onde estão centradas atividades e informações organizadas por área de conhecimento em arte.

Fase presencial 1: neste espaço estão disponibilizados os materiais utilizados na fase presencial 1 .

Fase EAD: espaço onde os alunos acessam as unidades de estudo que contém os conteúdos e atividades.

Fase presencial 2: espaço destinado às atividades do momento final presencial.

\section{Resultados}

A procura pelo curso, como se poderia imaginar, foi significativa, apresentando o número de cento e setenta e sete (177) inscritos advindos de diferentes áreas de formação. Diante disso, um processo seletivo foi realizado com o objetivo de proporcionar formação àqueles que de fato atuam com o ensino de Arte. Este fato trouxe dos polos, onde realizavam suas inscrições a solicitação de que cursos para outras áreas de atuação fossem oferecidos, assunto que foi remetido àqueles que poderiam suprir esta demanda. Dentre os inscritos, foram matriculados oitenta e oito (88) alunos e, destes, sessenta e um (71) finalizaram o curso. A busca por esta formação foi maior entre professores com formação em pedagogia. Suas expectativas giravam em torno de conhecer técnicas e atividades que poderiam ampliar suas práticas, sob o formato de "receitas prontas", em sala de aula. No entanto, buscou-se ampliar o conhecimento acerca da Arte a partir de vivências que proporcionassem ampliação de sua leitura do mundo e um novo olhar sobre as ações e conteúdos de Arte nas práticas escolares. Os resultados podem ser conhecidos a partir dos relatos de alguns alunos:

"Através do curso pude aprimorar meus conhecimentos que me ajudaram no planejamento diário."

"Construímos juntos um conhecimento precioso com troca de ideias"

"Pensar na arte como um leque de possibilidades que relaciona-se com todos os outros conteúdos. Ferramentas que utilizarei para apresentar o estudo da arte pensando nos limites e caminhos que ela pode nos levar, visualizando as possibilidades, diferenças e riquezas que existe no mundo." 


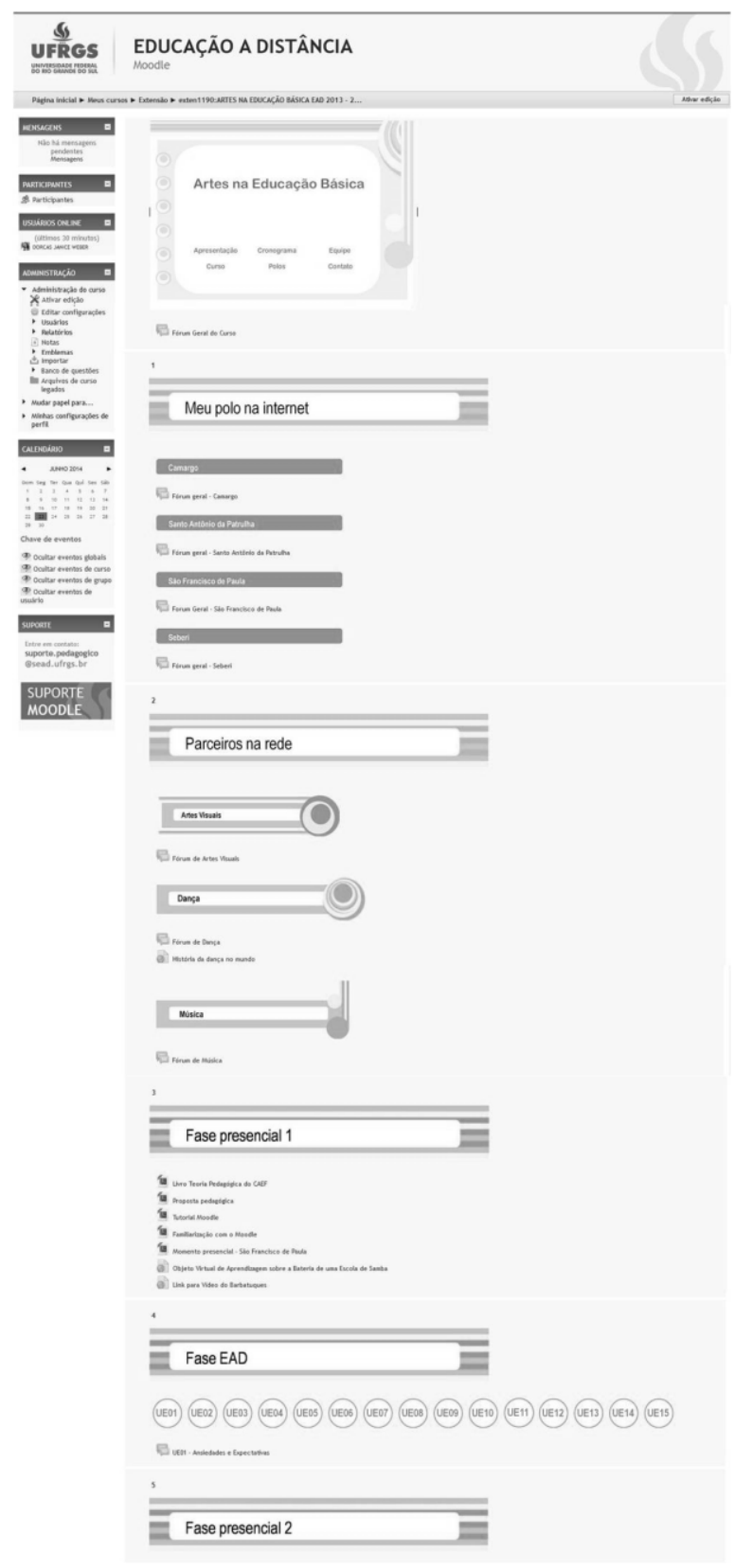

Figura 1. AVA do curso.

"Troca de ideias e experiências que possibilitam ser multiplicadores desses ensinamentos."

"Muita leitura, pesquisa e muita aprendizagem. Conhecemos de modo geral um pouco mais sobre vários tópicos dentro das Artes. Momentos de prazer e troca de conhecimentos."

"Consegui aprender diferentes temas relacionados as artes, assim como, suas curiosidades, sua importância na sociedade."

"As informações enriqueceram o conhecimento e outras coisas eu nem imaginava. O mais importante foi que os temas abordados levaram em consideração o cotidiano."

"Esses meses foram para mim momentos de: ansiedade, preocupação, leitura, estudo e muito esforço. A fundamentação teórica das UE foi de muita profundidade."
"Arte possibilita a expressão pessoal e cultural, permitindo a análise social da realidade, seja através de obras de arte ou por meio da criatividade e autoria. $\mathrm{O}$ curso possibilitou uma maior criatividade, autonomia, criticidade e nas minhas aulas de Artes. Ao mesmo tempo, pode proporcionar aos sujeitos atitudes de compromisso, respeito e valorização da diversidade cultural, nas aulas de Artes. No mundo de hoje, são inúmeras as possibilidades no fazer artístico, que propiciam a inovação, a motivação, responsabilidades, compromisso e respeito, que facilitam uma relação comprometimento entre aluno, professor, escola e sociedade. Desta forma, fazer arte é muito mais que do que saber utilizar pincel e tinta; é conhecer a história; é projetar-se na obra. Através da Arte é possível reviver um momento e transformá-lo em realidade a ser apreciada, criticada e planejada de formas."

"Ver diferentes linguagens...ter experiências novas e produzi-las com os nossos alunos. Arte é poderosa linguagem produtora de autoestima, criticidade e imaginação."

"Grande aprendizado, pois a cada eixo trabalhado, novos conhecimentos se fizeram presentes, tenho a declarar que o crescimento cultural foi muito grande. Minha aprendizagem foi muito visível, pois pude perceber meu crescimento nesta área".

\section{Comentários finais}

O ensino de Arte no espaço escolar vem mostrado um aglomerado de ações superficiais e que caracterizam a Arte por atividades decorativas e que lembram datas comemorativas. Parte desta situação pode ser compreendida ao observar a formação dos professores que atuam com conteúdos de Arte. Muitos deles, sem formação adequada, fazem uso de suas vivências, como alunos, para compor as atividades que conduzem para seus alunos, criando assim, um círculo vicioso que replica a cada ano as mesmas atividades. Alguns professores buscam na formação continuada a solução para estabelecer o repertório de atividades práticas, afinal, o histórico desta disciplina constitui-se de ações práticas, pouco reflexivas e o estudo de aspectos teóricos relativos à Arte. Neste contexto, foi criado um curso para oferecer formação para professores que atuam com Arte na escola e que possuem pouca, ou nenhuma, formação para tal. O objetivo foi apresentar a eles uma formação inicial e geral, que proporcionasse a eles vivencias que ampliassem sua concepção sobre o ensino de Arte na escola.

$\mathrm{O}$ curso foi oferecido em regiões onde não existem cursos de formação em nível de graduação em nenhuma das linguagens de arte. Fato que levou professores de diversas áreas para as inscrições, mesmo entendendo que o curso propunha a formação do individuo e não a oferta de opções de atividades para serem aplicadas, foi feita uma seleção entre os inscritos para que as vivências fossem centradas naqueles que, de fato, iriam aplicá-las na sala de aula. A oferta na modalidade semipresencial foi um desafio inicial para muitos professores, porém, após um encontro de formação e o uso gradual das ferramentas do AVA, os alunos 
adaptaram-se facilmente a esta modalidade, o que levou a um resultado de sessenta e nove por cento de alunos no término do curso.

Ao final desta edição os alunos compreenderam que a formação continua em Arte não necessita oferecer atividades prontas, mas que a formação do professor enquanto individuo que observa o mundo de modo ampliado e compreende a importância da arte no desenvolvimento das pessoas, é um passo para que ele próprio possa construir suas proposições e a partir de então oferecer uma educação de qualidade e satisfatória para todos os envolvidos.

\section{Referências}

Arslan, L. M.; Iavelberg, R. (2006). Ensino de Arte. São Paulo: Thomson Learning.

Barbosa, A. M. (2005). A imagem no ensino de arte. São Paulo: Perspectiva.

Brasil. (1996). Lei de Diretrizes e Bases da Educação Nacional. Acesso em 14 de maio de 2015 de http://portal.mec.gov.br/arquivos/pdf/ldb.pdf.
Brasil. (1996). Parâmetros Curriculares Nacionais Arte. Brasília: MEC/SEF. Acesso em 14 de maio de 2015 de http://portal.mec.gov.br/seb/arquivos/pdf/ livro06.pdf.

Coutinho, R. G. (2008). A Formação de Professores de Arte. In Barbosa, A. M. (2008) Inquietações e Mudanças no Ensino de Arte. Ana Mae Barbosa (org.). São Paulo: Cortez. P.153 - 159.

Debord, G. (1977). A Sociedade do Espetáculo. Rio de Janeiro: Contraponto.

Moran, José Manuel. Integração das tecnologias na educação. Disponível em http://www.eca.usp.br/prof/ moran/integracao.htm. Acesso em 24 jul 2010.

Pourtois, J.; Desmet, H. (1997). A Educação PósModerna. Lisboa: Horizontes Pedagógicos.

UNESCO. (2010). Educação um tesouro a descobrir: relatório para a UNESCO da Comissão Internacional sobre Educação para o século XXI. Disponível em http://www.dominiopublico.gov.br/download/texto/ue 000009.pdf. Acesso em 02 ago 2010. 